\title{
ORIENTATION AND MIGRATION IN THE SEA
}

\author{
A Symposium organized by the Marine Biological Association and the Society for \\ Experimental Biology, and held at the University of Plymouth, 18-21 April, 1994
}

\section{Abstracts of papers and posters presented}

\author{
EDITED BY R. WILLIAMSON
}

Marine Biological Association

\section{PAPERS}

\section{Multisensory control of eye orientation in freely moving and passively transported crabs}

\author{
W.J.P. Barnes and H. Paul ${ }^{1}$
}

Department of Zoology, University of Glasgow, Glasgow, G12 8QQ. ${ }^{1}$ Biokybernetik Department, Universität Tübingen, D-7400 Tübingen, Germany

Although crabs do not fixate and track objects of interest, they do exhibit well developed compensatory eye movements that occur in response to a variety of mechanosensory and visual cues. In freely walking crabs, such eye movements compensate well for body turns, but are weak or absent during pure sideways locomotion. Crabs thus compensate for the rotatory but not the translatory components of visual flow. Here we address two features of this behaviour: first, the multisensory nature of the compensatory eye movements that occur in response to body rotation; and second, the reasons why translatory locomotor movements do not give rise to high gain compensatory eye movements.

The importance of visual, statocyst and leg proprioceptive inputs in producing good compensation for turns was studied by measuring the eye positions and body orientation in the yaw plane of land crabs, Cardisoma guanhumi under the eight possible combinations of blind/seeing, with/without statocysts, freely walking/passively transported. The results indicate that good compensation for turns only occurs when all three sensory inputs are present, absence of any one input resulting in a significant decline in the effectiveness of the compensation. Likewise, no single visual mechanisms seem to be responsible for preventing eye movements occurring during translation. Optokinetic gain is reduced by the presence of stationary contrasts, movement in anterior/posterior rather than lateral parts of the visual field, narrow rather than wide spacing of visual contrasts, and differences between the inputs seen by the two eyes. It thus appears that separation of the rotatory from the translatory components of the flow field involves every available sensory cue, but how crabs use the information so gained has yet to be elucidated. 


\title{
The medial division of the pineal window may be used for solar orientation in
} Atlantic salmon Salmo salar

\begin{abstract}
O.K. Berg ${ }^{1}$ and T. Nordtug ${ }^{2}$
${ }^{1}$ Department of Zoology, University of Trondheim, N-7055, Norway. ${ }^{2}$ The Arts and Science Research Foundation in Trondheim, Gryta 2, N-7010 Dragvoll, Norway

The pineal window of Atlantic Salmon, Salmo salar (fork length $25-55 \mathrm{~cm}$ ) is highly transparent with values of transparency ranging up to about $3 \%$ for the smaller fishes. The window consists of two plates, each forming a flat, elongated, bony structure. Both plates form a roof-like structure with the ridge parallel to the main body axis. In the central part of the pineal window these plates meet with a mean angle of $120^{\circ} \pm 5^{\circ}$. On each side of the bony pineal plates there is a relatively thin, white lining which may act like an optical diffuser. The transparent area of the pineal plates is peripherally limited by a dark pigmented layer.

A preparation of the pineal window was used to investigate the angle dependent transmission of light. From light emitted in the pineal groove, a scanner with a sensor, registered the light transmitted through the pineal window. Each pineal plate integrates the incident light relative to the corresponding hemisphere and directs the rays onto the pineal organ. The angle of maximum transmission is $-30^{\circ}$ and is symmetrical through the window on both sides of the body axis. The division of the light is gradually reduced when the incident light is aligned towards the front or rear of the fish. The optical properties of the pineal window results in light from both halves of the sky being separated and projected onto the pineal body from two different directions. At the position of the pineal body the angle is about $60^{\circ}$ between the axes of maximum intensity of light from the two halves of the sky. This division is caused by the reduced transparency for light entering the skull from the directions near parallel to the vertical plane through the body axis of the fish relative to incident light from lateral directions.

In spite of the light scattering properties of the pineal window, a polarization factor of 0.60 was found in the pineal groove for linearly polarized incident light.

Information derived from both the polarization-plane and for hemispherical integration of light may be used for orientation processes. The possible specific pineal perception of these properties of the light is not known. The hypothesis is proposed that these properties of the pineal window have ultimately evolved as a directional aid enabling the fish to orient by the directionality of the sunlight.
\end{abstract}

\section{Predicting migration with foraging theory: movements of juvenile plaice in shallow water}

\section{M.T. Burrows}

\section{Dunstaffnage Marine Laboratory, PO Box 3, Oban, Argyll, PA34 4AD}

Recent developments in foraging theory allow prediction of behavioural decisions as functions of the state of an animal from the influence of alternative actions on this state. State can represent the level of energy reserves, but it may also incorporate spatial position. Decisions to move in particular directions affect the future state of the fish, bringing it into areas of abundant food, safe from predators, or for spawning.

This approach has been used in a model of migration of juvenile plaice in shallow water. Distributions of prey and predators were used to predict migration and foraging patterns in a range of conditions: from Scottish beaches with more prey subtidally to Wadden Sea shores with more prey in intertidal areas. The predicted tidal and diurnal movements agree well with those observed at these sites.

Adult plaice use pelagic swimming for migration, and recent evidence suggests that juvenile plaice may also do so. Pelagic swimming will reduce numbers of encounters with prey and with bottom-dwelling predators, whilst benthic swimming brings the fishes into contact with both their prey and their predators. If feeding is visually mediated, the model predicts that plaice should use pelagic swimming to migrate at night to avoid predators, and benthic swimming by day to remain in contact with their prey. 


\title{
Experimental and field studies on the role of individual behaviour on sole transport in the Bay of Biscay
}

\author{
Gisèle Champalbert ${ }^{1}$ and Constantin Koutsikopoulos ${ }^{2}$
}

${ }^{1}$ Centre d'Océanologie, URA 41, Faculté de Luminy, 13288 Marseille Cedex 8, France. ${ }^{2}$ IFREMER, BP 1049, 44037 Nantes Cedex 1, France

In the Bay of Biscay, pelagic stages of the common sole, (Solea solea L.) are characterized by a relatively stable spatial and temporal distribution. Eggs and larvae remain over the spawning grounds located 40 to $80 \mathrm{~km}$ offshore.

To try to understand the mechanisms that may influence transport to coastal nurseries, experimental studies on larval and juvenile behaviour have been carried out They mainly concerned orientation reactions and swimming activity with respect to light, current, pressure and feeding conditions.

Several experimental methods were used: visual observations with an infrared converter, actographic methods using infrared barriers, video-camera equipment and automatic recordings. Different types of tanks fitted with special devices to vary light and pressure were utilized. The effects of current were studied in an hydrodynamic flume.

Based on these laboratory experiments and field studies we propose and discuss hypothesis involving both active movement and diffusive processes to explain sole onshore transport during ontogenesis. Vertical movements are strongly influenced by endogenous factors and light that synchronizes the rhythm of activity. Pressure, current and feeding conditions also modify swimming activity and orientation.

\section{Homing patterns in intertidal molluses}

\author{
G. Chelazzi
}

Department of Animal Biology and Genetics, University of Florence, I-50125 Florence, Italy

Resting in a more or less constant scar to protect themselves from various physical and biotic critical factors and making foraging excursions at set intervals is a common general pattern well known in several gastropods and chitons living on rocky substrata in the intertidal zone. However, the homing pattern may assume different characteristics in the different species with regard to: degree of fidelity to a constant scar; temporal alternation of resting and moving away; geometrical characteristics of the foraging excursions; organization of foraging activity within each excursion. Recent experimental studies conducted with ad hoc monitoring techniques in the field and under controlled laboratory conditions allowed precise assessment of both temporal and spatial characteristics of homing patterns in chitons and gastropods, showing ecologically important variations at both intra- and inter-specific level. In particular, there is increasing evidence that goal-oriented movements based upon self-informing mechanisms (trail following, home marking) are involved not only in homing after each foraging loop, but also in relocating suitable foraging sites during subsequent excursions. Recent implementations of actographic, motographic and sonographic techniques are described and examples are given of homing patterns in chitons and limpets.

\section{Movement patterns of lobsters (Homarus gammarus) in Poole Bay, UK}

\author{
K.J. Collins, E.K. Free and A.C. Jensen
}

\section{Department of Oceanography, University of Southampton, Southampton, SO9 $5 \mathrm{NH}$}

Poole Bay, central south coast UK, has a sedimentary sea bed with rocky patchy reefs which are fished commercially for lobsters and crabs. A small experimental artificial reef comprising 8 units was constructed in 1989 on flat ground in the Bay some $3 \mathrm{~km}$ distant from any rocky habitat. This was rapidly colonized by both lobsters and crabs. A tagging programme was started in 1990 marking animals both on the natural and artificial reefs. Some 3500 lobsters have been tagged with a first recapture rate of over $30 \%$. The majority of distances moved have been small scale and generally aligned with tidal flow. 
Conventional tagging has shown that lobsters have been resident on the reef for over 3 years. In order to determine more detailed movement patterns, ultrasonic and more recently, electromagnetic telemetry have been used to track lobsters. During the summer of 1993-4, animals were tracked continuously for 2 months. Movement generally took place at night. Distinct patterns involving considerable interchange between reef units were seen. Extended excursions away from the reef were observed, the duration varying from hours to weeks. These observations suggest that lobsters have the ability to orientate within their immediate environment.

\section{Movement of decapod crustaceans, a life cycle adaptation to a seasonal environment}

\section{Gérard Y. Conan ${ }^{1}$, Donald R. Maynard ${ }^{2}$, Patricio E. Arana ${ }^{3}$ and Pierre Mallet ${ }^{1}$}

${ }^{1}$ Department of Fisheries and Oceans, Gulf Fisheries Centre, Moncton New Brunswick, E1E 3W7, Canada. ${ }^{2}$ Jacques Whitford Ltd, 4 Walker Drive, Unit G, Charlottetown, Prince Edward Island, C1A 4P3, Canada. ${ }^{3}$ Escuela de Ciencias del Mar, Universidad Católica de Valparaíso, Casilla 1020, Valparaíso, Chile.

Original data and existing literature on the snow crab, Chionoecetes opilio, the Norway lobster, Nephrops norvegicus, the American lobster, Homarus americanus, and the spiny lobster Jasus frontalis, show that decapod crustaceans may adapt to seasonal environmental conditions by movements specific to each stage of their life cycle. For instance, berried females may move into warmer water, this enhances egg development rate, or move close to a thermocline at egg hatching time, this allows larvae to reach a layer of water with favourable hydrological conditions.

In regions affected by different seasonal environments, the seasonal pattern of movements of Homarus americanus differ. However, these behavioural variations do not appear to characterize distinct genetic sub-populations.

The signals initiating seasonal movements are not limited to simple changes in temperature or photoperiodism. Adult Chionoecetes opilio live far below the euphotic zone in an infrathermoclinal, seasonally stable environment, yet their seasonal movements closely adapt to conditions favourable to spawning and to development of the larvae. The signal appears to be of chemical origin and result from the rain of organic material resulting from the spring phytoplankton bloom.

Most adult Homarus americanus remain within a radius of $10 \mathrm{~km}$ year after year; however, some individuals may move upstream of an oceanic current over their life span. The movements appear to be the net result of a wandering activity that can be monitored by sonic tag rather than a well defined migration. This is possibly related to scavenging by following a chemical path flowing downstream from quarries, as documented by tagging and underwater video observations. The effect may contribute to compensate for larval drift.

A seasonal spring incursion from deep into shallower water, followed by hatching of the eggs, and/or moulting, and a later return into deeper water below a thermocline is well documented for Jäsus frontalis and Chionoecetes opilio. This has also been reported for several other species of spiny lobsters and majid crabs. Laboratory experiments suggest that decapods may thus adjust seasonally their metabolic rates to food availability. Higher temperatures allow for swifter movements and faster gonadal or somatic growth at the cost of higher metabolic expenses. Deep colder water reduces metabolic expenses when food is less readily available.

\section{Molecular tracking of planktonic larvae}

\section{D.R. Dixon ${ }^{1}$, H.B.S.M Corte-Real ${ }^{1,2}$, D. Jollivet ${ }^{1}$, L.R.J. Dixon ${ }^{3}$ and P.W.H. Holland ${ }^{2}$}

${ }^{1}$ Plymouth, Marine Laboratory, Citadel Hill, Plymouth, PL1 2PB. ${ }^{2}$ Department of Zoology, University of Oxford, South Parks Road, Oxford, OX1 3PS. ${ }^{3}$ Marine Biological Association, The Laboratory, Citadel Hill, Plymouth, PL1 2PB

A significant number of marine invertebrate species inhabiting shallow-water and deep-sea environments have planktonic larvae which spend differing amounts of time swimming or drifting free in the water column. The length of time spent in the plankton ranges from just a few days to several months depending on the species. An obvious benefit derived from planktonic larval dispersal is the ability to colonize new areas over a wide range; this is particularly 
important for those organisms which inhabit marine environments typified by spatial and/or temporal heterogeneity.

We have developed a novel molecular approach to planktonic larval analysis, with the aim of increasing our understanding of the influence of ecological and biological factors on dispersal and gene flow in a range of different marine environments. Our first attempts employing a polymerase chain reaction (PCR)-based strategy have proved successful in allowing the analysis of DNA sequence length variation within gene introns (i.e. non-coding, and potentially neutral, DNA sequences) in single larvae of the mussel, Mytilus edulis. This has enabled us to detect evidence of restricted gene flow between mussel populations on the west and north-east coasts of Britain, and for local effects around the Thames estuary.

Currently, we are extending these investigations to include the larval stages of deep-sea hydrothermal vent organisms. Our intention is to investigate the role of larval dispersal in generating and maintaining the patterns of biogeographical and genetic differentiation observed in hydrothermal vent communities in different parts of the globe. Hydrothermal vent habitats are characterized by a high degree of temporal and spatial instability. In order to exploit the chemical energy at the vents, the specialized vent fauna has had cope with this highly unstable and patchy environment. Vent communities display significant levels of biogeographical differentiation between oceanic ridges on a spatial scale measured in thousands of kilometres, indicating efficient powers of dispersal within and between vent fields $(<1$ to 10 s of kilometres apart) and across vent segments separated by hundreds of kilometres. Since the larval stages are too small to analyse by conventional (i.e. allozyme) methods, and in some cases these are impossible to identify to the species level based on morphological criteria, this requires the application of sensitive new molecular techniques. In this presentation we report on our first attempts to develop a PCR-generated molecular database to aid in the identification of larvae of hydrothermal-vent organisms. An instrument to sample planktonic larvae from around hydrothermal vents for molecular analysis is currently under development.

\title{
Escape trajectories in various animals
}

\author{
P. Domenici ${ }^{1}$, R.S. Batty ${ }^{1}$ and R.W. Blake ${ }^{2}$
}

${ }^{1}$ Dunstaffnage Marine Laboratory, PO Box 3, Oban, Argyll, PA34 4AD. ${ }^{2}$ Department of Zoology, University of British Columbia, Vancouver, British Columbia, V6T 1Z4, Canada

When startled, animals escape away from a stimulus more often than towards it. Although escape trajectories are linearly related to stimulus direction, they show considerable variation. Past studies on animal escape trajectories have employed linear plots of stimulus angle versus body turn. Here, we employ circular statistics to analyse our own data on some fish species and reanalyse data from published studies on other animals. Circular histograms of escape trajectories show multimodal distributions that differ significantly from random and normal circular (von Mises). The multimodal form of these distributions is not apparent from the linear plots. These multiple preferred escape trajectories correspond to particular orientations of the animals' sensory organs relative to the stimulus. Multiple escape trajectories may prevent predators from learning a single fixed prey response and compensating for it.

\section{Light as a factor regulating the vertical migration and reproduction of the benthic amphipod Monoporeia affinis}

K.O. Donner and M. Lindström

Department of Zoology and Tvärminne Zoological Station, PO Box 17, SF-00014, University of Helsinki, Finland

The amphipod Monoporeia (Pontoporeia) affinis, a glacial relict in northern Europe, is found on soft bottoms of the Baltic Sea at depths from 10 to $200 \mathrm{~m}$. At night the animals become pelagic and swim freely around. Laboratory experiments show, using infrared recording techniques, that this behaviour is released by the absence of light. Light 'off' acts as a Zeitgeber at intensities higher than an incidence of about 2 photons per ommatidium of the eye per second. The eye has $40-50$ ommatidia and a spectral sensitivity with its maximum at $550 \mathrm{~nm}$ as measured with the ERG as an 
index. The spectral sensitivity maximum coincides with the maximum for downwelling light, A corresponding visual pigment has been found by microspectrophotometry. The ERG threshold of the fully dark-adapted eye is close to the behavioural threshold mentioned above. It corresponds to the light intensities prevailing at noon at depths around $80 \mathrm{~m}$. Reproduction normally occurs in November-December. However, summer breeding has been found to occur at depths below $80 \mathrm{~m}$ where the animals even in full daylight should have no perception of light.

\title{
Long range movements and navigation in marine mammals
}

\author{
M.A. Fedak, B.J. McConnell and A.R. Martin
}

Sea Mammal Research Unit, Natural Environment Research Council, Madingley Road, Cambridge, CB3 OET

The development of miniature data loggers and satellite-link telemetry now allows the foraging movements and behaviour of marine mammals to be investigated in detail over extended periods on a global scale. As well as demonstrating extreme dive depths, unexpected dive durations and limited surface time, recent data has documented directed long range movements in a number of species. Foraging ranges of some species can cover large fractions of entire ocean basins. Within species, patterns of movement are often highly variable but tracks of particular individuals are often repeated with remarkable faithfulness. Tracks give evidence of impressive navigational skill, even while animals travel at great depth, during periods of darkness in murky water or under extensive ice cover. We give examples for four species which document these abilities. The senses and 'landmarks' used for navigation and the strategy with which they are used is not yet obvious. In addition, the ocean is a dynamic, patchy environment. At any given location, productivity and food availability can be variable from year to year. Thus, on its own, an ability to navigate to a specific location may not be rewarded by successful foraging. Navigational ability must be combined with the abilities to interpret cues from their environment which will lead to prey concentrations.

\section{Migrations of the Baltic mysids and their relation to predation by fish}

\section{J. Flinkman, I. Hakala, H. Salemaa and P. Välipakka}

\section{Department of Zoology, PO Box 17, SF-00014, University of Helsinki, Finland}

Mysid shrimps (Mysidacea, Crustacea) are dominant members of crustacean fauna in the brackish waters of the northern Baltic Sea. The non-migratory species Praunus flexuosus and $P$. inermis as well as the Pontocaspian neoimmigrant Hemimysis anomala have distinct patterns of behaviour and habitat selection in the phytal belt. Neomysis integer is most abundant on shallow soft and sandy bottoms, their shoals migrating between littoral and coastal waters. Littoral mysids are summer breeders in the northern Baltic periphery. This results in considerable seasonal fluctuations in their qualitative and demographic characteristics as regards to their role as food for littoral fish.

Two species of Mysidacea, Mysis mixta and M. relicta inhabit the open waters. Mysis species are winter breeders in the northern Baltic Sea. Nocturnal migrations, induced by light, are characteristic to both species. Young individuals and $M$. mixta swim highest towards the surface. Vertical migrations are most extensive in the spring and early summer, the period of reduced feeding activity of open water fish, especially the Baltic herring.

\section{Orientation mechanisms and pressure sensing in crabs}

\section{P.J. Fraser}

Department of Zoology, University of Aberdeen, Tillydrone Avenue, Aberdeen, AB9 2TN

Crabs have a specialized balancing organ, the statocyst which contains at least three types of sensory hair involved in the normal orientation of the animal. The ways in which these provide information during walking and swimming are discussed. In common with many Crustacea, crabs have been shown to respond to small pressure changes in the range expected to be encountered by the animal during movements in the tidal domain. Considerable behavioural evidence exists, but the sensor for pressure monitoring has not been identified. One problem in 
considering possible sensors is the lack of a gas filled space in the crab which would allow pressure changes to be easily translated into volume changes and hence displacements sufficient to be sensed by mechanoreceptors. I report here that statocyst afferents are sensitive to small step changes in pressure, and discuss the possible transduction mechanism and the ways in which the information could be separated from acceleration information carried by the same afferents.

\title{
Temporal and spatial patterns in the diel vertical migration of the copepod Metridia lucens
}

\author{
G.C. Hays, A.J. Warner and C.A. Proctor
}

The Sir Alister Hardy Foundation for Ocean Science, The Laboratory, Citadel Hill, Plymouth, PL1 2PB

It has been suggested that diel vertical migration may provide a metabolic advantage associated with movement across a thermocline or reduce the risk of mortality from visually orientating predators. The strongest evidence supports the predator-evasion hypothesis with migration also being influenced, in certain situations, by food availability. We used a total of 9635 zooplankton samples, representing $178,552 \mathrm{~km}$ of towing, collected over a 45 year period (1948-1992) to describe the diel migratory behaviour of the copepod Metridia lucens in the North Atlantic. In accord with the predator-evasion hypothesis the length of time $M$. lucens was present near the surface varied seasonally, being shorter in the summer coincident with shorter nights. However, $M$. lucens spent longer at the surface in spring and less time in autumn than expected from the night length. In addition, there was a latitudinal variation in the seasonal timing of this enhanced occupation of the surface waters in spring which paralleled the latitudinal development of the spring phytoplankton bloom. This observed pattern may therefore reflect enhanced reproductive fitness derived from being at the surface for longer at the onset of the spring phytoplankton bloom.

\section{Vertical migration in tidal flows}

\author{
A.E. Hill
}

School of Ocean Sciences, University of Wales, Bangor, Menai Bridge, Gwynedd, LL59 5EY

Vertical migration may interact with purely oscillatory tidal currents to produce net horizontal transport. Most obvious is selective tidal stream transport which occurs when vertical migration is specifically synchronized with tidal currents so that organisms ascend into the water column on flood tides, say, but settle onto the bed, or descend to depths where currents are weak when the tide turns. Commonly, however, vertical migration is synchronized not with the tide, but with the day-night cycle. Diel migration in tidal currents has some important, though less obvious, transport-producing effects. (1) Diel migration in $\mathrm{M}_{2}$ period tidal currents induces no net horizontal transport over a fortnight but can produce excursions of several tens of kilometres over just a few days. (2) Diel vertical migration is predicted to interact with the sun-generated part of the semi-diurnal tide to produce net horizontal transport, the direction of which is controlled by the phase of $\mathrm{S}_{2}$ tidal currents. The spatial distribution of phase implies that regions of horizontal convergence and divergence will result from diel migration. (3) Diel migration in diurnal-period tides causes the preferred direction of transport to reverse at six monthly intervals.

\section{Movement patterns and migrations in crabs: telemetry studies of juvenile and adult behaviour in Callinectes sapidus (Portunidae) and Maja squinado (Majidae)}

\author{
A. Hines ${ }^{1}$, T. Wolcott ${ }^{2}$, E. González-Gurriarán ${ }^{3}$, J.L. González-Escalante ${ }^{3}$ and J. Freire ${ }^{3}$
}

${ }^{1}$ Smithsonian Environmental, Research Center, PO Box 28, Edgewater, MD 21037, USA. ${ }^{2}$ Department of Marine, Earth and Atmospheric Sciences, North Carolina State University, Raleigh, NC 27695 USA. ${ }^{3}$ Departamento de Bioloxía Animal, Universidade da Coruña, E-15071 Coruña, Spain

Using ultrasonic telemetry, we compared the movement of juveniles and adults of two species of crabs that differ in habitat and life histories. Blue crabs Callinectes sapidus (Portunidae) were tracked in a shallow ( $<4 \mathrm{~m}$ ) soft-bottom sub-estuary of Chesapeake Bay (western Atlantic, USA). 
Movements of spider crabs Maja squinado (Majidae) were measured in the Ría de Arousa (eastern Atlantic, NW Spain), in a large depth range $(2-60 \mathrm{~m})$ of hard and soft bottom habitat.

Callinectes juveniles (90-110 mm carapace width) utilize near shore shallows $(<1.5 \mathrm{~m}$ deep) within small (0.05-1 ha) areas along the shoreline. At 1-5 day intervals they move $0.5-1.0 \mathrm{~km}$ along shore or across deeper $(2-4 \mathrm{~m})$ water to new near shore locations. Large $(>120 \mathrm{~mm}) \mathrm{crabs}$ utilize deeper (1-4 m) water, meandering within larger areas $(0 \cdot 1-1 \cdot 0 \mathrm{ha})$. At intervals of about $2-$ 5 days they move rapidly $1-5 \mathrm{~km}$ along the axis of the sub-estuary before settling down to meander within a new area or moving back into the main estuary. Maja juveniles (70-130 mm. carapace length) utilize shallow $(2-10 \mathrm{~m})$ rocky substrate in near shore kelp beds, where they exhibit movement within small areas (0.1-1.0 ha). In late summer, after the pubertal moult, young adults (130-200 mm) gradually extend their range of movement into deeper $(5-15 \mathrm{~m})$ areas. In autumn and early winter, adults migrate to greater depths $(>30 \mathrm{~m})$ offshore.

Juveniles of both species are restricted to near shore zones, where small crabs obtain food and refuge from predation in the shallows along the water's edge, Callinectes or among rocks and algae, Maja. With the onset of sexual maturity, both species increase their range and speed of movement. The shift in habitat utilization as the crabs mature probably reflects differences in selective pressures affecting juvenile (predation avoidance, growth optimization) and adult stages (increased food requirements, reproductive maximization).

\title{
Movement of juvenile and adult Dover sole Solea solea L. in the Bay of Biscay: role of coastal environment and spawning migration
}

\author{
C. Koutsikopoulos, D. Dorel and Y. Desaunay
}

IFREMER, Centre de Nantes, BP 1049, 44037 Nantes Cedex 01, France

During the studies on sole recruitment in the Bay of Biscay, transport process attracted considerable attention and led to important researches on migration and dispersal. The last step to complete the study of the spatial component of the life cycle of sole in the northern part of the Bay of Biscay is the offshore migration of adults towards the spawning grounds. The present study deals with this pre-spawning migration. The main question concerns the kind of linkage between nurseries and spawning grounds. The principal results are based on extensive tagging experiments carried out in autumn 1992 in two distinct nursery grounds, Bay of Vilaine and Pertuis (4620 soles of 2-group and older). One year later (January 1994) catches of tagged individuals reached $18.4 \%$ and $12 \%$ of the initial samples respectively. From September to February a $30 \mathrm{~km}$ net displacement of the gravity centre of the population was exclusively observed towards the offshore deeper area. A small trend to move onshore appeared in spring. In parallel with these net movements the individuals were dispersed around the gravity centre of the population. This dispersion was higher in the parallel to the coast direction. During this second phase, individuals from different nurseries were mixed over the same spawning areas of the Biscay Bay and some individuals were also captured in and close to the English Channel. Changes in distribution were in phase with environmental changes and some elements concerning topographic preferences also appeared. Some evidence for orientation observed but random dispersal seemed more important. No particular link between a spawning ground and a nursery in the vicinity appeared. This observation suggests that the behaviour of the Bay of Biscay sole stock, considered as a whole, depends on the individual nurseries dynamics and the rate of exchanges between nurseries.

\section{Diel vertical migration of freshwater and marine zooplankton: are there differences?}

W. Lampert

\section{Max Planck Institute for Limnology, Postfach 165, D-24302 Plön, Germany}

Although the mechanisms have been more extensively studied in fresh waters, there is more and more evidence that predator avoidance is the ultimate cause of DVM of zooplankton both in the sea and in lakes. Patterns of DVM are variable, but the differences can be explained as differences in the trade-offs controlling migration behaviour. Predictions of the predator-avoid- 
ance hypothesis hold in both habitats; for example, DVM is related to fish abundance, large individuals have a stronger tendency to migrate than small ones, the abundance of food can modify the migration pattern, a large predator that migrates can cause a reverse migration in small zooplankton. There may, however, be differences in the perception of predators by zooplankton. Chemical cues (kairomones) released by fish have been demonstrated in freshwater to 'motivate' the zooplankton response to light controlling DVM. Although the role of chemical cues in the sea cannot be excluded, there is experimental evidence for a mechanical stimulus produced by foraging fish.

\title{
Orientation and tracking by hyperiid amphipods
}

\author{
M.F. Land and N.J. Marshall \\ School of Biological Sciences, University of Sussex, Brighton, BN1 9QG
}

Many meso-pelagic animals have large eyes and presumably use them in a variety of ways. Very little is known of their natural behaviours, however, because of the difficulties of observing them. Hyperiids have very large compound eyes, and behave well when brought to the surface. Using a tank backlit with IR light and a Video system, we were able to present the animals with a variety of stimuli and observe their reactions in near-dark conditions. Various species had previously been shown to respond occasionally to light and dark bars, but in this paper we describe much more striking and reliable behaviour to a blue light emitting diode. Brachyscelus sp. swarmed around the LED as soon as it was switched on, and both Phrosina semilunata and Phronima sedentaria tracked the LED convincingly as it moved. They did this either by tilting the body axis towards the LED, or swimming along with it, a few body lengths away. Interestingly, the part of the eye used to track the LED was not the dorsal acute zone in the upper eye, but a frontal region of slightly elevated acuity in the lower eye. This is consistent with the idea that the upper eye views dark objects against the residual daylight whereas the lower eye is concerned with luminescent objects.

\section{Factors affecting the horizontal migration of the benthic amphipod Monoporeia affinis}

M. Lindström

\section{Tvärminne Zoological Station, SF-10900 Hanko, Finland}

The amphipod crustacean Monoporeia (Pontoporeia) affinis is common on soft bottoms of the Baltic Sea. Because of its great abundance and high nutritional value, it forms an important link in the food chain. The animal swims actively at night and stays in the bottom sediment in daytime. During the active swimming phase $M$. affinis migrates horizontally in respect to water currents or temperature gradients. This has been investigated in the laboratory in long, narrow aquaria equipped with recording devices working in the infra-red. Also video recordings, using infra-red light, have been used. In response to a water current the animals swim against the direction of the current. Small temperature gradients, within the interval $2-6^{\circ} \mathrm{C}$, leads to an aggregation of the animals in the warmer end of the aquarium. The intensity of swimming decreases with increasing temperature. The type of bottom substrate influences the preference for active swimming, which is higher over unfavourable bottoms. The very act of swimming in a certain direction seems to become stronger during the animal's descent to the bottom just before, or at, the onset of light. connected.

\section{Use and detection of wave cues by sea turtle hatchlings}

\author{
C.M.F. Lohmann, K.J. Lohmann and A.W. Swartz
}

Department of Biology, Coker Hall CB-3280, University of North Carolina, Chapel Hill, NC 27599-3280, USA

After emerging from nests on shore, hatchling sea turtles enter the sea and begin a migration towards the open ocean. To test the hypothesis that migrating hatchlings use wave cues to maintain their seaward orientation, we released turtles offshore under conditions of varying 
wave direction. Measurement of vanishing bearings indicated that hatchlings swam into approaching waves in all experiments, even when doing so resulted in landward headings. These data suggest that, in the early phase of their migration, hatchlings maintain seaward headings by using the direction of wave approach as an indicator of the seaward direction. Because waves are refracted towards land in shallow coastal waters, swimming into waves reliably results in orientation towards the open sea.

A turtie swimming underwater might have difficulty determining wave direction visually, but could, in principle, detect the motion induced by the passage of a wave. An object (or a turtle) in a water column beneath the surface of the ocean describes an orbital movement as a wave passes above. Theoretically, an animal swimming underwater might therefore detect wave direction by monitoring the sequence of accelerations it experiences. Such a mechanism, however, has never been demonstrated in any animal.

In hatchling sea turtles, the swimming motor program is activated when the turtle's flippers fail to contact substrate; thus, hatchlings suspended in air will 'swim' indefinitely. To determine if hatchlings can detect wave direction by monitoring acceleration sequences, we constructed a wave simulator to reproduce in air the circular movements that a swimming turtle would normally encounter beneath ocean waves. Responses of hatchlings subjected to simulated waves from various directions were videotaped under infrared light to eliminate visual cues. Results indicated that hatchlings exposed to acceleration sequences simulating waves approaching from their right sides attempted to turn right, whereas simulated waves from the left consistently elicited left turning. Acceleration sequences simulating waves from directly in front of the animal elicited virtually no turning. The results clearly demonstrate that hatchling sea turtles can determine the direction of ocean waves by monitoring the sequence of accelerations that occur as waves pass above. This mechanism may be widely used by other open sea migrants such as fish and cetaceans.

\title{
Detection of magnetic inclination angle by sea turtles: a possible mechanism for determining latitude
}

\author{
K.J. Lohmann and C.M.F. Lohmann
}

Department of Biology, Coker Hall CB-3280, University of North Carolina, Chapel Hill, NC 27599-3280, USA

For animals that migrate long distances, the magnetic field of the earth provides not only a possible cue for compass orientation, but a potential source of world-wide positional information. At each location on the globe, the geomagnetic field lines intersect the earth's surface at a specific angle of inclination. Because inclination angles vary with latitude, an animal able to distinguish between different field inclinations might, in principle, determine its approximate latitude. Such an ability, however, has never been demonstrated in any animal.

We studied the magnetic orientation behaviour of hatchling loggerhead sea turtles, Caretta caretta L. exposed to earth-ștrength magnetic fields of different inclinations. Hatchlings exposed to the natural field of their natal beach swam eastward, as they normally do during their offshore migration. In contrast, those subjected to an inclination angle found on the northern boundary of the North Atlantic gyre (their presumed migratory path) swam south-south-west. Hatchlings exposed to an inclination angle found near the southern boundary of the gyre swam in a northeasterly direction, and those exposed to inclination angles they do not normally encounter were not significantly oriented.

These results demonstrate that sea turtles can distinguish between different magnetic inclination angles and perhaps derive from them an approximation of latitude. Most sea turtles nest on coastlines that are aligned approximately north-south, so that each region of nesting beach has a unique inclination angle associated with it. We therefore hypothesize that the ability to recognize specific inclination angles may largely explain how adult sea turtles can navigate back to their natal beaches after years at sea. 


\title{
Migration and orientation of plaice (Pleuronectes platessa) in the southern North Sea
}

\author{
J.D. Metcalfe, G.P. Arnold, B.H. Holford and A.A. Buckley
}

Directorate of Fisheries Research, Ministry of Agriculture Fisheries and Food, Fisheries Laboratory, Lowestoft, Suffolk, NR33 OHT

Sonar tracking of individual fish tagged with transponding acoustic tags has shown that plaice can move long distances by selective tidal stream transport. Fish move into mid-water at one slack-water and return to the bottom at the next slack-water, about six hours later. This tidallylinked pattern of vertical movements results in rapid movement in a consistent direction along the tidal stream paths.

Mid-water trawling experiments in the southern North Sea confirm that maturing adult plaice use this mechanism to migrate between feeding grounds near the Dogger Bank to spawning grounds off the Dutch coast and in the eastern English Channel. The direction of migration depends on maturity stage of the fish: maturing plaice use the tidal stream to move south and spent fish use the opposing tidal stream to return north.

A comparison of the movement of migrating fish over the ground with the predicted speed and direction of the tidal stream shows that plaice generally head down-tide during periods in mid-water. A more detailed analysis of data obtained from plaice equipped with acoustic tags which telemeter the compass heading of the fish shows that plaice are able to orientate by using some non-visual, external directional clue. The ability to orientate down-tide when in mid-water could allow migrating plaice to reduce substantially the metabolic cost of migrating.

\section{Migration in cephalopods}

\section{J.B. Messenger}

\section{Stazione Zoologica, Villa Communale, I-80121 Naples, Italy}

Many cephalopods, like other marine animals, make extensive movements in the sea, vertically and horizontally. Diel vertical migrations can extend over hundreds of metres; they are believed to be driven by light, but may also be related to movements of prey and predators. In many pelagic cephalopods the young inhabit the top layers of the sea and then progressively descend the water column as they grow. There is some evidence for ontogenetic migrations in the opposite direction.

Horizontal migrations of squids have been reported in many seas of the world: they have been especially well documented in Japan, using tag-and-release methods, but migrations along the eastern seaboard of North America and along the Pacific coast of South America have also been studied. Such migrations take place over thousands of kilometres, and there seems to be a pattern of movement of higher latitudes for feeding and a return to lower latitudes for reproduction.

It is not known what triggers these horizontal migrations, nor is it understood how cephalopods orient and maintain orientation during migration. They may rely mainly on visual cues, for cephalopods have large eyes and polarized light sensitivity. Could mechanical information about the direction of water currents, detected by the lateral line analogue, also be utilized? Could there be magnetic orientation in cephalopods?

\section{Movements of spider crabs (Maja squinado) around Jersey}

\author{
C.G. Meyer ${ }^{1}$ and M.B. Jones
}

Department of Biology, University of Plymouth, Drake Circus, Plymouth, PL4 8AA. ${ }^{1}$ Present address: Hawaii Institute of Marine Biology, University of Hawaii, PO Box 1346, Hawaii, USA

Catches of Maja squinado (Herbst) from Jersey (1990-93) help clarify current knowledge of seasonal migrations of this commercially-exploited spider crab in the Normano-Breton Gulf (south-west English Channel). A trap study in a known inshore nursery area (Belcroute Bay) revealed a seasonal pattern of juvenile numbers and size composition. Catch per unit effort (number of crabs per 100 traps) corresponded with sea-water temperatures, and was low in 
winter, increased through spring to a peak in summer and declined during autumn. Winter catches consisted predominantly of relatively small juveniles (15-50 mm carapace length) and larger juveniles (60-120 mm carapace length) dominated at other times. Hard-shelled adults also occurred in the nursery catches but only during spring and early summer. This finding is consistent with the proposed annual reproductive migration of $M$. squinado which brings adults inshore at this time. There was a two-month lag in the seasonal patterns of occurrence of hardshelled and recently-moulted adults in nursery area catches, which suggests that recentlymoulted adults move offshore later than hard-shelled adults. Differences in migration times explain the seasonal depth partitioning known from commercial traps from other areas around Jersey which show that juvenile and recently-moulted spider crabs over winter in shallow water $(10-20 \mathrm{~m})$ and catches in waters $>20 \mathrm{~m}$ consist mainly of hard-shelled adults

\title{
The orientation of tail flip escape swimming in decapod and mysid crustaceans
}

\author{
D.M. Neil ${ }^{1}$, A.D. Ansell ${ }^{2}$, S.A. Arnott ${ }^{1}$ and K. Smith ${ }^{1}$ \\ ${ }^{1}$ Department of Zoology, University of Glasgow, Glasgow, G12 8QQ. ${ }^{2}$ Dunstaffnage Marine Laboratory, \\ PO Box 3, Oban, Argyll, PA34 4AD
}

The orientation of tail flip escape swimming has been examined in a range of decapod and mysid crustaceans in response to artificial mechanical stimuli delivered under experimental conditions and produced by fishing gear, and in response to predator attacks under natural conditions.

In mechanical terms, tail flip swimming constitutes unsteady locomotion in which a single 'appendage', the abdomen, produces thrust by a combination of a rowing action and a final 'squeeze' force when the abdomen presses against the thorax.

Tail flip flexion is controlled by two giant fibre pathways, and also by a non-giant neuronal network. The direction of thrust in the sagittal plane, and hence the elevation, translation and rotation of the tail flip are dependent upon the point of stimulation and on the giant fibre pathway activated.

The laterality of the stimulus also affects the orientation of swimming, which is directed away from the point of stimulation. In large decapods such as the lobsters Nephrops and Jasus steering is produced by asymmetrical movements of various abdominal appendages, and by rotation of the abdomen about the thorax. In smaller decapods such as the brown shrimp Crangon and the mysids there is a rapid rotation of the whole body about its longitudinal axis during the initial stages of flexion.

\section{Homing of yellow phase American eels in a strong tidal estuary}

\author{
S.J. Parker
}

\section{Department of Zoology, University of Maine, Orono, ME 04469-5751, USA}

Yellow phase American eels were displaced $10-15 \mathrm{~km}$ and followed to determine the degree of home site fidelity, swiftness of homing and if environmental factors affect orientation or homing behaviour. Twenty-three eels were tracked (eight displaced up river, eight down river and seven controls) in the Penobscot Estuary. Each eel was tracked continuously for 4-80 h, mean=49 h), while recording position plots every $20 \mathrm{~min}$ for a total of $1121 \mathrm{~h}$ of tracking and 3288 position plots. Simultaneous measurements of hydrographic and meteorological variables were made every $40 \mathrm{~min}$ at the location of the fish. Nine of the 16 displaced eels (56\%) returned to within 200 $\mathrm{m}$ of their capture site either during the track or shortly afterwards as determined by subsequent daily position checks. Three of the remaining seven eels made substantial progress towards their capture site within the time observed. Eels homed equally if displaced up river or down river and did so in an average of $216 \pm 88 \mathrm{~h}$. The eels moved mostly at night and used appropriate tidal currents, rather than directed swimming, making the time spent actively homing much shorter. Control tracks provided a home range estimate in this habitat of $6.64 \pm 1.63 \mathrm{~km}$ of river. This study shows that orientation and homing to a specific site occurs relatively quickly and with no initial orientation errors. 


\title{
Causal explanations and physiological mechanisms of diel vertical migration (DVM): a comparison of marine and freshwater organisms
}

\author{
J. Ringelberg \\ Department of Aquatic Ecology, University of Amsterdam, Kruislaan 320, 1098 SM Amsterdam, The \\ Netherlands
}

Physiological mechanisms have been evolved, pressured by adaptive needs. Factors triggering these mechanisms can be different from selective forces and thus a distinction has to be made between both.

At the base of DVM is a vector with velocity and direction. Thus, migration behaviour consists of kinetic mechanisms with movement initiating stimuli and orientation mechanisms with directing stimuli, respectively.

Orientation: In Daphnia the complex eye becomes fixed to the light-dark boundary of the Snellius Circle. The body axis rotates with regard to the eye axis such that an upward or an obliquely downward direction is maintained. Eyes of copepods are different but contrast orientation is present at least in Eudiaptomus gracilis.

Kinesis: Up and downward swimming in Daphnia and Acartia is a phototaxis initiated by relative changes in light intensity. In the field, morning descend and evening rise coincide with maximum values of this stimulus at dawn and dusk. DVM of scattering layers seems also to be correlated to these light changes. In some marine and freshwater animals, exudates of visually predating fish enhance phototaxis and are conditional for well expressed migrations. In this way, causal mechanisms and adaptive significances are connected.

\section{Reflections of light and fast pulses of sound as methods of signalling between fish}

D.M. Rowe ${ }^{1}$ and E.J. Denton ${ }^{2}$

${ }^{1}$ School of Computing, University of Plymouth, Drake Circus, Plymouth, PL4 8AA. ${ }^{2}$ Marine Biological Association, The Laboratory, Citadel Hill, Plymouth, PL1 2PB

For fish like the herring, mackerel, horse mackerel and sand eel, schooling is such an important part of their lives that it would be surprising if special mechanisms for giving information on their movements to their neighbours did not exist. Two such mechanisms are: informative light reflections and fast pressure pulses.

The first depends on the special properties of submarine illumination whereby a 'vertical' mirror is almost invisible, whereas an inclined one is very visible. Reflective platelets over large areas in the surface of the fish are oriented so that combinations of yaw, pitch and roll present characteristic changing patterns of brightness, and sometimes of colour and polarization, to their neighbours. Silvery fish commonly also have small special reflective areas, often on the tail, pectoral fins, lateral lines and around the eye. Some give information on the fish's movements in the form of bright and 'dark' flashes, which will be very visible to near but not to distant observers. Others are only visible from certain directions. Diffuse reflecting surfaces can, to some degree, serve the same purpose, but are less good at doing so. Fast pressure pulses, generated during quick movements, can give much more rapid, but less informative information than can reflective layers.

\section{The migration of returning adult Atlantic salmon Salmo salar $L$. in coastal waters}

\author{
G.W. Smith, G.G. Urquhart, A.D.F. Johnstone and A.D. Hawkins
}

SOAFD Marine Laboratory, PO Box 101, Victoria Road, Aberdeen, AB9 8DB

Atlantic salmon, Salmo salar L., are generally anadromous, spending the first years of their life in freshwater before migrating to sea as smolts and returning to their natal river one or more years later to spawn. The mechanisms involved in the oceanic and coastal migrations of salmon are not clear, and the degree to which homing is achieved by random search or involves active navigation towards the natal river is a matter of some debate. In order to describe the detailed movements of returning adult Atlantic salmon in coastal waters, and to test whether homing is 
achieved by direct orientation to the home river, or by random search, the movements of individual acoustically tagged fish have been analysed.

Returning adult salmon caught in the sea along the east coast of Scotland were tagged with ultrasonic transmitters, released and their movements observed. The tidal movements of water in the vicinity of the fish were also monitored. In further experiments to relate the movements of fish to the location of their home river, salmon which had recently entered the River North Esk were displaced back to sea, tagged with an ultrasonic transmitter, released and their individual movements observed.

Although, at some distance from the coast (mean $8.05 \mathrm{~km}$ ), salmon movements relative to the ground were complex and appeared strongly affected by tidal movements, vector analysis removing the deflecting influence of the tide showed that salmon were generally capable of maintaining a constant heading relative to the water (directional movement) for up to 28 hours. At closer distances (mean $<4 \mathrm{~km}$ ) progress relative to the coast was independent of tidal phase (coastal following), but was occasionally disrupted in areas of river outflow. Salmon displaced to sea after entering the River North Esk did not orientate in the direction of the river on release, but were nevertheless subsequently found to be capable of homing to the vicinity of the river. It is concluded that salmon may rely upon a searching strategy to complete the final phase of their return migration to the natal river, and that the observed coastal following behaviour may be understood as maximizing the salmon's probability of encountering home stream cues from river outflow.

\title{
An integrated view of the environmental factors influencing glass eel ascent
}

\author{
C. Sola and P. Tongiorgi
}

\section{Dipartimento di Biologia Animale, University of Modena, I-41100 Modena, Italy}

Using a binary choice apparatus, we investigated the role of the environmental factors temperature, salinity and odour in the last phase of glass eel migration towards freshwater. All the examined parameters influence glass eel behaviour. The animals prefer flows of a temperature equal to or lower than that to which they are acclimatized, they can distinguish small differences in salinity favouring lower concentrations, and they are attracted by natural surface water odours. Among the chemical substances which can act as an odorous cue, vegetable odorants are particularly important. These odorants occur in the ground and surface freshwater and only reach the sea via the river flows. In freshwater, their unique green, musky or earthy odour is extremely attractive to glass eels, while solutions in water of a salinity equal to that of the sea have either no effect or are avoided. As soon the salinity falls below that of the open sea water, the avoidance reaction disappears, while attraction depends on both salinity and odour concentrations. Any of these three factors may play a predominant role in a particular phase of glass eel approach to the river mouth; however, their synergy is fundamental for correct orientation in the changeable conditions of the estuaries.

\section{Migration of the Mediterranean slipper lobster Scyllarides latus}

\section{E. Spanier}

The Recanati Center for Maritime Studies, University of Haifa, Haifa, 31905, Israel

A tagging study of the Mediterranean slipper lobster Scyllarides latus (Latreille, 1803) in artificial habitats off the coast of Israel indicated that they demonstrated two types of movements. During the lobster season (February-June in the south-eastern Mediterranean) they left the shelters at night while performing short term movements to forage and bring back food-bivalves to the site. Lobsters left artificial reefs, where they were tagged during spring, and returned only in the following winter. There are indications that the lobsters performed long-term migration to deeper water and towards the north. It is suggested that this migration is associated with physiological and/or behavioural adaptations for moulting that occur during fall. These lobsters do not have any morphology for active defence. The flat bottom of the shallow continental shelf of the south-eastern Mediterranean contains limited habitats that supply preferred shelters for these crustaceans. It is assumed therefore that it is advantageous for lobsters to return to the sites 
that offer better protection against diurnal predators. The mechanism by which they orient and locate these preferred habitats is unknown.

\title{
Vertical movements of migrating silver eels in the sea
}

\author{
F.-W. Tesch
}

Biologische Anstalt Helgoland, Notkestraße 31, D-22607 Hamburg, Germany

Data on the descending and ascending of eels tracked in the Mediterranean and in the Baltic were analysed in more detail. Diving down immediately after being released in the Mediterranean, down to a maximum depth of $103 \mathrm{~m}$, was comparatively fast and, as a mean of 11 eels, $72 \mathrm{~cm}$ $\mathrm{s}^{-1}$; in the shallower Baltic the corresponding values for 11 eels were $46 \mathrm{~m}$ and $46 \mathrm{~cm} \mathrm{~s}^{-1}$. Later vertical movements were slower (in the Mediterranean 7-25 $\mathrm{cm} \mathrm{s}^{-1}$ ). The eels in the Mediterranean started descents and ascents at a significantly lower speed than that at which they moved during the middle parts of their vertical movements. In all four eels tracked for a sufficiently long time during vertical movements, increasing depth resulted in a decrease in speed; it became zero at a certain maximum depth $(603 \mathrm{~m})$. The return to shallower depths showed, as expected, no significant difference between the mounting speed in greater and shallower depths. The vertical activity, as tracking progressed, generally decreased, in the Mediterranean as well as in the Baltic. Towards the shallower depths along the Baltic coastline, the number of dives to the bottom increased. Night and daylight generally did not produce significantly different vertical activity. There is no significant correlation between vertical and horizontal swimming speed.

\section{Magnetic orientation in and near the sea: Idotea baltica, Talitrus saltator and Talorchestia martensii}

$$
\text { A. Ugolini }
$$

\section{Dipartimento di Biologia Animale, University of Firenze, Via Romana 17, I-50125 Firenze, Italy}

Under certain conditions, the sun is one of the most common orienting cues for ecotonal Arthropods ( $\mathrm{Y}$ axis orientation). However, the sun is not always present (even during the day), and could therefore be difficult to use. In particular, the speed of the sun in equatorial regions is far from constant during the day, and the sun's declination also changes twice a year.

It has recently been demonstrated that in a confined, dry environment, the equatorial sandhopper T. martensii possesses a good magnetic compass which it uses alongside the solar one. The marine isopod I. baltica from the Mediterranean Sea also has a magnetic compass and the direction of the $Y$ axis can be learned using the EMF as an orienting cue. T. saltatoris even more intriguing: North European individuals possess the magnetic compass, but our recent findings show that adult individuals from the Mediterranean do not: they perceive the EMF but in laboratory releases alternate between 4 azimuthal positions $90^{\circ}$ apart.

We conclude that regardless of latitude, EMF sensitivity could be a common feature in crustaceans with $Y$ axis solar orientation and a good reference for up-dating the sun compass.

\section{Diel vertical migration in Meganyctiphanes norvegica: influence of endogenous rhythm and light}

Jean Philippe Velsch and Gisèle Champalbert

Centre d'Océanologie de Marseille, Station Marine d'Endoume, CNRS/UA 41-13007, Marseille, France

A detailed study of the diel vertical migration of Meganyctiphanes norvegica (Crustacea, Euphausiacea) was carried out in the north-western part of the Mediterranean Sea.

Day-night plankton samples were collected simultaneously or successively at different depths using opening-closing Orinets equipped with an acoustical release system.

$M$. norvegica was found mainly between 40 and $80 \mathrm{~m}$ during the night and between 650 and 850 $m$ during the day.

To understand the variations of migratory behaviour observed in the sea, and the mechanisms underlying diel vertical migrations in Meganyctiphanes norvegica, experiments have been carried 
out in laboratory. They concerned the swimming activity and the effects of light on this swimming activity and the orientation reactions.

Several techniques were used: Actography and automatic detection with infrared barriers to record vertical movements; Infrared video systems to record activity; parallel light beam associated with specific device and infrared converter to study phototaxis.

Under natural dark-light conditions, Meganyctiphanes norvegica exhibits a rhythmic activity with a maximum at the surface of the experimental tank during the night. In total darkness, an endogenous rhythm appears with a period around $23 \mathrm{~h}$. Phototaxis is negative between 2000 and $2 \times 10^{15} \mu \mathrm{W} \mathrm{\textrm {cm } ^ { 2 }}$, and neutral at lower illuminations.

The influence of endogenous rhythm and light on DVM in Meganyctiphanes norvegica and ecological consequences are discussed.

\title{
Clues for the orientation of eel in the Baltic
}

\begin{abstract}
Håkan Westerberg
National Board Fisheries, Nya Varvet Hus 31, Västra Frölunda, Sweden

Eels are common in the whole Baltic drainage area and have to pass through this relatively large body of water on their return migration. 15 years of daily catch statistics from 10 places in the southern Baltic together with more than 30 telemetry trackings of silver eels are used to discuss possible orientation clues. An almost universal behaviour of eels released close to land is an initial departure away from the coast followed by a longshore movement at several $\mathrm{km}$ distance. The relation between catch rate and wind direction and the observed behaviour of eels tracked in the vicinity of a strong low-frequency sound source suggest that acoustic information is important in the coastal environment.

Eels tracked in the open Baltic move in the upper layer on straight courses for long periods of time. A relation seems to be present between the timing of catch peaks and the propagation of internal Kelvin waves along the Swedish coast. Together with the anomalous behaviour of anosmic eels this indicates that hydrographic information is used in the open water orientation.
\end{abstract}

\section{A sensory basis for schooling in Antarctic krill}

\section{K. Wiese ${ }^{1}$ and Y. Ebina ${ }^{2}$}

${ }^{1}$ Zoologisches Institut, Universität Hamburg, Martin Luther King Platz 3, D-20146 Hamburg, Germany. ${ }^{2}$ Department of Electrical Engineering, Yamaguchi University, Ube 755, Japan

The fascinating smooth metachronal motion of the five pairs of swimmerets of Euphausia superba produces a powerful propulsion jet to lift and move the non-buoyant shrimp. Comparable free-jets of circular cross-section extend for considerable distances into a resting body of water and hence are suitable as communication signals among conspecifics, e.g. to serve in recruitment to schools and in securing fixed positions of individuals within schools. To prove the hypothesis we recorded the propulsion jet of $E$. superba by a special low-pressure sensitive microphone. FFTanalysis shows characteristic frequency bands, multiples of the beat frequency of appendages, in the range $2-25 \mathrm{~Hz}$.

The shrimp is able to analyse the spectrum by a proprioceptive multi-unit scolopal mechanoreceptor located at the basal hinge of two of the four antennular flagella of Euphausia. It shows an electrophysiologically measured threshold to flow at $70 \mu \mathrm{m} \mathrm{s}^{-1}$. An estimated 100 sensory cells respond to low frequency turbulence with one to more spikes per cycle from 0.5 to above $30 \mathrm{~Hz}$. The two remaining flagella form a sensory balance that detects the orientation of the axis of a flow field.

Swimmerets moving in parallel to fast moving water (produced by conspecifics swimming in front) are ineffective in producing propulsion. Hence, instead of swimming in line, individuals do best in following conspecifics at staggered positions.

Staggered positions are the intersections of the fringe turbulences of two neighbouring propulsion jets. Flow field visualization by added ink shows the water at intersections to turn in narrow circles, bring the jet motion to an effective halt. This site and condition, presumably detected by antennular sensors, provides the abutment necessary for effective operation of swimmerets. 


\title{
A sensory basis for orientation in cephalopods
}

\author{
R. Williamson \\ Marine Biological Association, The Laboratory, Citadel Hill, Plymouth, PL1 2PB
}

All forms of cephalopod orientation, whether it is with respect to gravity in maintaining an upright and streamlined body posture during swimming, or with respect to the environment in locating breeding or feeding grounds over long distances, have a sensory basis. In this short review we will look at the sense organs involved in orientation with a view to providing a basis for understanding the mechanisms involved.

As in many other animals, vision is probably the most important sense involved in orientation. Cephalopods have paired eyes, sometimes providing binocular vision, and, with the exception of the pin hole eyes of Nautilus, generally similar to those of many vertebrates in terms of their gross structure and performance. The main feature apparently lacking in cephalopods is colour vision, but in compensation many have polarized vision.

The second most important sense in cephalopods is the sense of balance provided by the statocysts. These paired organs, are functionally similar to the vertebrate vestibular system, and detect both linear and angular accelerations, giving the animal information on its spatial orientation and rotational movements. The statocysts are also involved in the debate over hearing in cephalopods, for there is no doubt that they can detect minute vibrations carried in the water and ground. The recently discovered cephalopod lateral line system also detects water borne vibrations, but this is more likely used for locating other animals in low light conditions.

Behavioural experiments have shown that olfaction is also important in cephalopod orientation, but although there is good morphological data on the structures involved in olfaction, there is very little supporting physiological data.

Of the remaining senses used in orientation, touch is important for bottom living octopuses, but less so for the free swimming squids. There is no evidence, so far, for electroreception or magnetic sensitivity in cephalopods.

\section{Pelagic movements of Atlantic cod (Gadus morhua) during early spring in Trinity Bay, Newfoundland}

\author{
J.S. Wroblewski and W.L. Bailey
}

Fisheries Oceanography Group, Ocean Sciences Centre, Memorial University of Newfoundland, St John's, Newfoundland, A1B 3X7, Canada

Using depth-telemetering, sonic tags orally inserted into the stomachs of Atlantic Cod (Gadus morhua) found over wintering in Trinity Bay, Newfoundland, the movements of individual fish were observed when surface waters were first warming in early spring. Sonically-tagged fish spent most time in $0-2^{\circ} \mathrm{C}$, shallow waters. Cod swam pelagically in the thermocline over deeper, subzero waters. Pelagic swimming behaviour was initiated at sunset, and ended at sunrise. Movement was at times in the same direction as the tidal current, but swimming speeds were several times greater than the tidal flow. Nocturnal pelagic swimming was also observed later during the summer. Tracking confirms indications from plasma antifreeze protein levels that cold-adapted cod, having moved into warm, shallow waters in early spring do not return to subzero bottom waters for any appreciable time.

\section{Muscles that move both eyes together in squid}

\section{J.Z. Young}

\section{Department of Experimental Psychology, The Crossroads, Brill, Bucks, HP18 9TL}

In decapod cephalopods there are 13 or 14 extraocular eye muscles, controlled by 4 nerves, whereas octopods have 7 muscles and 7 nerves. The extra muscles of decapods are attached to the anterior and upper surfaces of the eyes and are concerned with convergent eye-movements for binocular vision during capture of prey by ejection of the tentacles. In squids Loligo two of the anterior muscles cross the mid-line so that contraction on either side moves both eyes together. 
These 'conjunctive muscles' have been found in nearly all squids examined, including in young Histioteuthis before the eyes differ in size. They are also present in the deep-sea Vampyroteuthis and in Spirula and are an ancient feature of decapod organization.

\title{
Endogenous tidal rhythms of vertical migration in newly hatched larvae of Carcinus maenas
}

\author{
C. Zeng and E. Naylor
}

\section{School of Ocean Sciences, Marine Science Laboratories, Menai Bridge, Gwynedd, LL59 5EY}

Endogenous tidal rhythms of vertical migration in holoplankton have been demonstrated so far only in a few estuarine forms. Present studies show endogenous tidal vertical migration rhythms in stage I zoea, an open sea stage, of the shore crab Carcinus maenas. The rhythms were recorded by infra-red actography in constant conditions, using larvae obtained immediately after hatching in the laboratory from freshly collected, egg-bearing females.

To identify hitherto unknown synchronizers of endogenous tidal rhythms in holoplankton, swimming behaviour patterns were recorded in zoeas newly hatched from isolated egg masses which had been exposed to various entrainment cycles. Eggs were taken from crabs which became berried in the laboratory. Entrainment in 12:12h light/dark cycles induced circadian vertical migration rhythms. However, exposure to successive $2 \mathrm{~h}$ episodes of water agitation every $12 \mathrm{~h}$ resulted in the expression of circatidal vertical migration rhythms. On the shore, berried $C$. maenas tend to remain near low water mark and it may be that exposure to wave action at low tide is the tidal synchronizer for larvae which are close to hatching. Possible adaptive advantages of tidal vertical migration will be discussed.

\section{POSTERS}

\section{Escape behaviour of the brown shrimp, Crangon crangon, in response to predation by juvenile cod}

\author{
S.A. Arnott ${ }^{1,2}$, A.D. Ansell ${ }^{1}$ and D.M. Neil ${ }^{2}$
}

${ }^{1}$ Dunstaffnage Marine Laboratory, PO Box 3, Oban, Argyll, PA34 4AD. 'Department of Zoology, University of Glasgow, Glasgow, G12 8QQ

The escape response of the brown shrimp Crangon crangon to juvenile cod consists of a series of multiple tail-flips stimulated by the approach of the predator. To investigate this response, individual shrimps (10-35 $\mathrm{mm}$ total length) were exposed to single O-group cod (61-105 $\mathrm{mm})$ in a circular enclosure approximately $28 \mathrm{~cm}$ in diameter and $17 \mathrm{~cm}$ deep. Encounters were video recorded from above, and the horizontal escape swimming trajectories of the shrimp analysed from the recordings.

The tail-flip of $C$. crangon involves an initial lateral rotation of the body about the anteroposterior axis; consequently escape swimming is directed predominantly in the horizontal plane. The angle of escape is largely determined by this lateral rotation, but responses differ depending on the direction of approach by the predator. Postero-lateral approaches always evoked an escape contralateral to the direction of approach by the cod. Relative to the initial orientation of the shrimp (head $=0^{\circ}$, tail $=180^{\circ}$ ), the direction of escape after the first $2 \mathrm{~cm}$ of tail-flipping lay between $85^{\circ}$ and $122^{\circ}$ (mean $=98 \cdot 3^{\circ}, \mathrm{SD}=11 \cdot 6^{\circ}, \mathrm{N}=10$ ). However, antero-lateral approaches produced both contralateral and ipsilateral escapes. Contralateral escape trajectories lay between $85^{\circ}$ and $133^{\circ}$ (mean $=105.7^{\circ}, \mathrm{SD}=13.5^{\circ}, \mathrm{N}=11$ ), whilst ipsilateral trajectories lay between $101^{\circ}$ and $155^{\circ}$ (mean $=126 \cdot 3^{\circ}, \mathrm{SD}=15 \cdot 1^{\circ}, \mathrm{N}=9$ ). 


\title{
The migrational need of a small crustacean
}

\author{
U. Fiedler \\ Institut für Meereskunde, Düsternbrooker Weg 20, D 2300 Kiel 1, Germany
}

In the Baltic Sea the crustacean Diastylis rathkei is one of the most abundant benthic organisms. Its population density varies between 1000 and 2000 indiv. $\mathrm{m}^{-2}$ on average with maximum values of 10,000 indiv. $\mathrm{m}^{-2}$ after reproduction. Part of the population of $D$. rathkei performs a vertical migration during the night, a phenomenon common also in other benthic peracarids. Among the advantages of a diurnal pelagic phase are colonization of new habitats, finding mating partners and dispersal of the offspring. In the deeper parts of Kiel Bay (western Baltic Sea) oxygen depletion occurs frequently during summer. Diastylis can avoid these adverse conditions by vertical migration. Traps were designed to study the migrational response of $D$. rathkei to lower oxygen levels. These traps catch the migrating individuals in separate chambers for upwards and downwards swimming specimens. The traps cover $0.5 \mathrm{~m}^{2}$ of sediment surface and were always exposed over night, the phase of migrational activity of $D$. rathkei. Migrational activity was observed all year through. Maximum activity was observed during summer oxygen depletion, even though Diastylis seems to be quite resistant to low oxygen concentrations. In the field Diastylis survived in sea-water of only $3 \%$ oxygen saturation. In this paper field data on migration of $D$. rathkei are presented and compared to results obtained from laboratory experiments on migration and respiration under different oxygen regimes.

\section{Migration by the crawfish, Palinurus elephas}

\section{E. Hunter}

\section{School of Biological Sciences, University College of Swansea, Singleton Park, Swansea, SA2 8PP}

Previous studies of the crawfish, Palinurus elephas (Fabr.), have been unable to distinguish whether low winter catches result from offshore migration or from reduced activity levels in response to falling sea temperatures. Furthermore, several mark-recapture studies have suggested that crawfish remain effectively stationary once recruited to adult grounds. However, relatively high crawfish catches by trawlers during late autumn, sometimes from the same haul, implies that an offshore winter migration does occur. This view is supported by hearsay accounts by fishermen and divers. Further historical accounts are documented of surface-swimming crawfish swarms

It is suggested that further studies involving the tracking of adult crawfish would greatly benefit description of behaviour in this species.

\section{LESLIE COOPER MEMORIAL LECTURE}

\section{Living clocks in the sea}

\author{
E. Naylor
}

\section{Marine Science Laboratory, Menai Bridge, Gwynedd, LL59 5EY}

The powerful dispersive forces of wave and tides pose serious problems for mobile animals of the seashore. Yet such creatures normally avoid being swept offshore or washed inland; they use their own internal timing mechanisms to predict and avoid unfavourable conditions. The lecture will discuss biological clocks and clock-based navigational mechanisms which are used by common coastal animals to permit dispersal from and return to preferred zones, by anticipation of the rhythms of environmental change. 